\title{
A PRODUÇÃO DE SENTIDO NO DISCURSO JORNALÍSTICO SOBRE A PANDEMIA DE COVID-19 NO BRASIL
}

\author{
The Production of Meaning La producción de sentido en el \\ About the Covid-19 Pandemic discurso periodístico sobre la \\ in the Brazilian Journalistic Discourse pandemia del Covid-19 en Brasil
}

\author{
Samuel de Carvalho Lima* \\ Instituto Federal de Educação, Ciência e Tecnologia do Rio Grande do Norte, \\ Campus Mossoró, Programa de Pós-Graduação em Ensino, Mossoró, RN, Brasil \\ Rafael Lira Gomes Bastos** \\ Universidade Federal do Ceará, Programa de Pós-Graduação em Linguística, \\ Fortaleza, CE, Brasil
}

\begin{abstract}
Resumo: Este artigo investiga como o discurso jornalístico se torna palco de disputa de diversos pontos de vista sobre a pandemia de Covid-19 no Brasil ao utilizar a voz da ciência, que se ampara no conhecimento científico, e a voz do idiota, que combate a voz da ciência. O corpus é constituído por cinco títulos e cinco leads de notícias sobre o tema, publicados no site do jornal Folha de S. Paulo entre 20 e 24 de março de 2020. A análise das relações dialógicas evidenciou que o discurso jornalístico se bivocaliza com o discurso científico, expressando a voz da ciência de maneira difusa; cria uma arena de disputa entre a voz da ciência e a voz do idiota, trazendo valorações anticientificistas quando se bivocaliza com o discurso bolsonarista; desacredita a voz do idiota, distanciando-se dela por meio do discurso citado, produzindo os efeitos de sentido sobre a Covid-19.
\end{abstract}

Palavras-chave: Dialogismo. Vozes sociais. Discurso jornalístico. Covid-19.

\begin{abstract}
This paper analyzes how the journalistic discourse becomes a stage for the discussions between different points of view about the Covid-19 pandemic in Brazil when using the voice of science, supported by scientific knowledge, and the voice of the idiot, when combats the former voice. Our corpus consists of five headlines and five leads about the theme, published on the website of the newspaper Folha de S. Paulo between March 20 and 24, 2020. The dialogical relations analysis showed that journalistic discourse comes to be a bivocalization in the scientific discourse, expressing the voice of science diffusely; creates an arena of discussions between the voice of science and the voice of the idiot, bringing anti-science valuations when bivocalizes itself with the Bolsonarist discourse; and discredits the voice of the idiot, standing off from it through the quoted speech, as well as producing the effects of meaning over the Covid-19.
\end{abstract}

Keywords: Dialogism. Social voices. Journalistic discourse. Covid-19.

\footnotetext{
* Doutor em Linguística pela Universidade Federal do Ceará (UFC). Docente permanente do Programa de Pós-Graduação em Ensino (POSENSINO) - UERN-UFERSA-IFRN. ORCID: https://orcid.org/00000002-7145-3686. E-mail: samuel.lima@ifrn.edu.br.

** Doutorando em Linguística no Programa de Pós-Graduação em Linguística - PPGL-UFC. ORCID: https://orcid.org/0000-0002-6828-5976. E-mail: rafael.lira.gomes@gmail.com.
} 
Resumen: Este artículo investiga cómo el discurso periodístico se convierte en escenario de disputas desde diferentes puntos de vista sobre la pandemia de Covid-19 en Brasil mediante el uso de la voz de la ciencia, que se apoya en el conocimiento científico, y la voz del idiota, que combate la voz de la ciencia. El corpus consta de cinco títulos y cinco leads de noticias sobre el tema, publicados en la portada Folha de S. Paulo entre el 20 y 24 de marzo de 2020. El análisis de las relaciones dialógicas mostró que el discurso periodístico se bivocaliza con el discurso científico, expresando la voz de la ciencia de forma difusa; crea una arena de disputa entre la voz de la ciencia y la voz del idiota, aportando valoraciones anticientíficas al bivocalizar con el discurso bolsonarista; desacredita la voz del idiota, distanciándose de ella a través del discurso citado, produciendo los efectos del sentido sobre Covid-19.

Palabras clave: Dialogismo. Voces sociales. Discurso periodístico. Covid-19.

\section{INTRODUÇÃO}

A notícia, como gênero do discurso da esfera jornalística, é caracterizada por ser um enunciado relativamente estável que se pretende objetivo e que traz uma informação nova e relevante para a sociedade, além de construir o imaginário coletivo, buscando influenciar seus interlocutores (BENITES; SILVA, 2015; DARDE, 2006; LONGHI; FERREIRA, 2018). Em tempos da pandemia de Covid-19 no Brasil e no mundo, diante da importância e da urgência do tema, as notícias cumprem o papel de orientar a sociedade para a preservação da vida humana e se tornam palco de disputa de diversos pontos de vista.

Bakhtin e o Círculo oferecem um aporte teórico-metodológico para compreendermos que os atos praticados pelos seres humanos são semiotizados discursivamente e se deixam revelar em enunciados concretos que carregam, por meio de vozes sociais, os mais variados posicionamentos sobre um dado objeto (OLIVEIRA, 2012). Para Bakhtin (2018), todo discurso é bivocal, por carregar diferentes posicionamentos e valorações sociais, ou seja, a presença do outro no enunciado é marcada por diversos pontos de vista. O que é feio ou bonito, bom ou mau, científico ou religioso materializa-se por meio dos mais diversos recursos linguísticos e discursivos que compõem a totalidade de sentido do enunciado. Para nós, o objeto de discurso Covid19 também se deixa tocar dialogicamente pelas diversas valorações sociais que constroem o todo de sentido sobre o tema.

Nesse contexto, o objetivo deste artigo é verificar como o discurso jornalístico se utiliza da voz da ciência, que se ampara no conhecimento científico, e da voz do idiota designada pelos autores para caracterizar o ponto de vista que combate a voz da ciência - na produção de sentidos sobre a pandemia da covid-19 no Brasil. Uma vez que o jornal Folha de S. Paulo constitui um veículo de comunicação de massa, sendo, inclusive, o de maior alcance nacional, suas notícias são capazes de promover reações-respostas nos leitores que necessitam de informações que possam garantir sua própria existência. Amparados nos princípios da Análise Dialógica do Discurso (ADD), analisamos cinco títulos e cinco leads de notícias publicados no site do jornal Folha de S. Paulo entre os dias 20 e 24 de março de 2020, flagrando a produção de sentido pretendida pelo discurso jornalístico sobre o tema em questão. 
Feitas essas considerações iniciais, além desta introdução, o artigo se encontra dividido em mais três seções: a seguir, apresentamos nossas escolhas teóricometodológicas, pautadas na concepção de dialogismo, enunciado e vozes sociais, bem como na sistematização da ADD para títulos e leads de notícias; posteriormente, realizamos a análise do corpus, flagrando as relações dialógicas entre as vozes sociais que disputam a consciência humana no que se refere ao objeto de discurso Covid-19 em tempos de pandemia no Brasil; por fim, apresentamos as considerações finais.

\section{ESCOLHAS TEÓRICO-METODOLÓGICAS}

Diante da complexidade e do alcance do pensamento de Bakhtin e o Círculo, pesquisadores brasileiros têm se apropriado dos pressupostos dialógicos com o intuito de oferecer uma sistematização do que denominamos Análise Dialógica do Discurso (BRAIT, 2016; ACOSTA PEREIRA; BRAIT, 2020; SOBRAL; GIACOMELLI, 2016; 2018; entre outros). Os estudos desses pesquisadores nos servem de lupa para a análise enunciativo-discursiva empreendida neste artigo para elucidar como o discurso jornalístico se utiliza de vozes sociais na produção de sentido sobre a pandemia de Covid19 no Brasil.

$\mathrm{Na}$ perspectiva dialógica, a linguagem é realizada por meio de enunciados concretos, que são elos na cadeia da interação verbal, produto "da interação de dois indivíduos socialmente organizados [...] A palavra é uma espécie de ponte lançada entre mim e os outros. Se ela se apóia sobre mim numa extremidade, na outra apóia-se sobre o meu interlocutor" (BAKHTIN/VOLOCHÍNOV, 2006, p. 114-115). A essência do pensamento dialógico, portanto, está posta na relação de alteridade eu-o-outro. A interação entre os indivíduos é o fator central para a produção dos enunciados e da objetivação exterior do signo linguístico, ideologicamente orientado, como uma totalidade de sentido. Segundo Bakhtin (1997, p. 295),

\footnotetext{
[...] antes de seu início, há os enunciados dos outros, depois de seu fim, há os enunciadosrespostas dos outros (ainda que seja como uma compreensão responsiva ativa muda ou como um ato-resposta baseado em determinada compreensão). O locutor termina seu enunciado para passar a palavra ao outro ou para dar lugar à compreensão responsiva ativa do outro.
}

Nesta perspectiva, cabe salientar que o outro, do ponto de vista bakhtiniano, não corresponde necessariamente ao parceiro imediato do diálogo face a face; mais que isso, "mesmo que não haja um interlocutor real, este pode ser substituído pelo representante médio do grupo social ao qual pertence o locutor" (BAKHTIN/VOLOCHÍNOV, 2006, p. 114). Esse aspecto nos é relevante para compreender as condições de produção da notícia, gênero discursivo secundário, cujos interlocutores são o jornalista e seu leitor, neste caso compreendidos como representantes médios de seus grupos sociais: dos que escrevem e dos que leem. Nessas condições, a palavra do locutor é sempre orientada para a resposta do interlocutor, mas não apenas, uma vez que ela também, ao mesmo tempo, já se relaciona com enunciados anteriores. Sendo assim, o enunciado é dialogicamente inseparável dos enunciados anteriores que o determinam, considerado uma reaçãoresposta na qual 
A palavra (e em geral, o signo) é interindividual. Tudo o que é dito, expresso, situa-se fora da "alma", fora do locutor, não lhe pertence com exclusividade. Não se pode deixar a palavra para o locutor apenas. O autor (o locutor) tem seus direitos imprescritíveis sobre a palavra, mas também o ouvinte tem seus direitos, e todos aqueles cujas vozes soam na palavra têm seus direitos (não existe palavra que não seja de alguém). A palavra é um drama com três personagens (não é um dueto, mas um trio). (BAKHTIN, 1997, p. 351).

Nessa dinâmica, nossa análise leva em consideração que o enunciado sempre responde a outros, refutando-os, confirmando-os, completando-os, baseando-se neles, supondo-os conhecidos; e, de algum modo, conta com eles para compor os efeitos de sentido. Sendo assim, o enunciado é constituído por vozes sociais que são compreendidas como "pontos de vista específicos sobre o mundo, formas da sua compreensão verbalizada, horizontes concreto-semânticos e axiológicos específicos" (BAKHTIN, 2015, p. 67), presença do outro no discurso do enunciador. O discurso, de tal modo, só pode ser entendido se soubermos "quem usa a língua para se dirigir a quem, em que contexto, incluindo momento, local, interlocutores e suas relações sociais" (SOBRAL; GIACOMELLI, 2016, p. 1078). Dessa forma, o discurso, sócio-historicamente constituído, bivocaliza-se com outros discursos, que, na teoria bakhtiniana, materializamse em enunciados/textos carregados de pontos de vista axiológicos, ou seja, de vozes sociais. Assim,

\begin{abstract}
A bivocalidade da palavra consiste na introdução/citação de palavras de outrem no próprio enunciado. Através dela, cada enunciado apresenta sempre uma perspectiva que é uma reação ao enunciado alheio, uma resposta, polêmica, estilização, evasiva, contradição, mas organizada num único enunciado. (GONÇALVES; AMARAL, 2017, p. 143-144).
\end{abstract}

Nossas palavras são, por assim dizer, reconstruções valorativas das palavras dos outros. "As palavras do outro, introduzidas na nossa fala, são revestidas inevitavelmente de algo novo, da nossa compreensão e da nossa avaliação, isto é, tornam-se bivocais" (BAKHTIN, 2018, p. 223). Elas nascem e se formam "em interação e em luta com o pensamento alheio, o que não pode deixar de refletir nas formas de expressão verbal do nosso pensamento" (BAKHTIN, 1997, p. 317). Em outras palavras, as relações dialógicas, objeto de nossa análise, são as condições necessárias para o surgimento do discurso bivocal, demonstrando o funcionamento da linguagem por meio de enunciados que se convertem, pela composição ideológica da língua, em posições valorativas de diferentes sujeitos no campo do discurso. As relações dialógicas são possíveis, então, entre enunciações ou até mesmo entre palavras, desde que estas sejam tomadas como "representante do enunciado de um outro, ou seja, se ouvirmos nela a voz do outro" (BAKHTIN, 2018, p. 210).

Ao tratarmos da pandemia de Covid-19 no Brasil como objeto do discurso jornalístico, percebemos que ela não fica alheia aos diferentes juízos de valor produzidos socialmente nessa esfera da comunicação. A produção de sentido sobre o tema tem variado em torno de dois polos: o primeiro se ampara no ponto de vista científico, orientando as condutas humanas pela via de argumentos pautados em pesquisas de natureza experimental; o segundo se ampara na negação do científico, surgindo como reação-reposta ao primeiro. Levando em consideração que a ADD, entre outras coisas, 
examina as relações dialógicas que se estabelecem entre as vozes sociais que lutam pela consciência do sujeito ao expressar seu posicionamento diante de um objeto de discurso, esses dois polos recebem, nas fronteiras desta pesquisa, as seguintes denominações: voz da ciência e voz do idiota.

A voz da ciência, como já assinalado, ampara-se no conhecimento produzido e divulgado pela esfera científica - por exemplo, os artigos publicados em periódicos especializados que reportam novas descobertas sobre a Covid-19 a fim de promover o combate ao vírus e de estabelecer políticas de preservação da vida humana (SHEREEN et alii, 2020; AHMED; MEMISH, 2020). A mídia brasileira, por sua vez, segundo Albarello e Pinheiro (2017), tem se empenhado em divulgar e popularizar o conhecimento científico. Dessa forma, percebemos que, no gênero notícia, o discurso jornalístico se bivocaliza com o discurso científico, expressando a voz da ciência para sustentar seu projeto de dizer.

Por outro lado, a voz do idiota combate o conhecimento cientificamente produzido. $\mathrm{Na}$ filosofia e na literatura, a voz do idiota já foi caracterizada como uma voz distante das vozes típicas, idílicas e românticas (DELEUZE, 1989; TINTINO FILHO, 2013). Nesse caso, o idiota se torna o sujeito despido de reconhecimento social validado pelo poder, e sua voz é a voz de quem é posto à margem. Vale salientar que o tom filosófico desterritorializa o uso dessa palavra, tornando-a adaptável a outros contextos. Desse contexto para o nosso, a voz do idiota se apresenta à margem do conhecimento científico, além de menosprezá-lo. Assim como há bivocalização entre os discursos jornalístico e científico, mencionada anteriormente, no gênero notícia o discurso jornalístico também se bivocaliza com o discurso bolsonarista, expressando a voz do idiota para desacreditála e construir a arquitetônica discursiva em torno da pandemia de Covid-19 no Brasil. Vale salientar que o discurso bolsonarista é compreendido como o discurso político e autoritário de implementação do projeto de poder da direita neoliberal conservadora no Brasil (cf. PAIVA; BATISTA JÚNIOR, 2019).

Metodologicamente, "Bakhtin é muito claro e até repetitivo em dizer que o objetivo da investigação nas Ciências Humanas é o de compreender as vozes sociais e suas relações dialógicas presentes nos enunciados concretos" (OLIVEIRA, 2012, p. 278). Amparados nessa orientação, analisamos as relações dialógicas entre a diversidade de posições sociais materializadas no horizonte concreto-semântico do discurso jornalístico, flagrando a inserção da voz do outro, que pode ser marcada por meio do discurso citado, tais como o discurso direto e indireto. Por outro lado, variedade de nexos na transmissão do discurso alheio "[...] jamais se esgota nos modelos gramaticais dos discursos direto e indireto: os meios de sua inserção, informação e relevo são assaz multiformes" (BAKHTIN, 2015, p. 132). Por isso, analisamos, também, as opiniões que materializam um determinado posicionamento ideológico e demais formas do discurso do outro, sejam elas ocultas, semiocultas ou difusas, mas que compõem a orientação dialógica do discurso. Similarmente a Sipriano e Gonçalves (2017), na análise das formas de transmissão difusa da voz do outro enfatizamos os acentos apreciativos expressos por meio dos recursos linguístico-discursivos, tais como os verbos, advérbios, adjetivos, entre outros. 
Diante do apresentado, construímos uma sistematização para a análise enunciativodiscursiva pautada na hierarquia topo-base, isto é, no método sociológico de análise linguística proposto por Bakhtin/Volochinov (2006). Tal método se inicia pela análise das interações sociais entre os interlocutores, levando em consideração as condições de produção dos enunciados; em seguida, analisam-se as formas que os enunciados assumem mediante a heterogeneidade dos gêneros do discurso; por último, realiza-se a análise linguística habitual para a elucidação das relações dialógicas situadas no campo do discurso. Salientamos que, embora apresentemos a sistematização de uma ADD para títulos e leads de notícias (Figura 1), ela pode ser adaptada a outros contextos discursivos, desde que assumam, também, que seus elementos sejam imbricados intimamente no estudo dos textos que compõem o corpus da investigação, assim como se imbricam as relações dialógicas de/entre qualquer discurso.

Contexto de Produção
Jornalista - Interlocutores

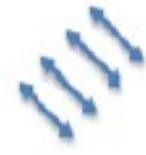

\section{Relações Dialógicas}

Corpus linguistico-discursivo

Títulos e Leads

$\uparrow 1$

\section{Análise Linguistica \\ Discurso Citado \\ Recursos Linguisticos \\ $11 \pm 11 \pm$}

Gêneros do Discurso

Notícia Jornalística

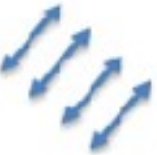

Figura 1 - Sistematização da ADD para títulos e leads de notícias

Fonte: autoria própria (2020).

Seguindo os procedimentos metodológicos assinalados, o corpus desta investigação é constituído por títulos e leads, elementos que integram a estrutura composicional do gênero notícia com a função de orientar e organizar a compreensão do que se pretende tematizar. Além disso, títulos e leads pressupõem fortemente a presença de seu interlocutor, pois "Quando evoca um acontecimento, o leitor, ao menos num primeiro momento, não está preocupado com detalhes, mas com a informação principal. É esta que de fato lhe interessa e, por isso, é esta que ele busca na manchete e no lead" (COMASSETO, 2001, p. 87).

O corpus de nossa análise é constituído por cinco títulos e seus respectivos leads do gênero discursivo notícia, publicados no site do jornal Folha de S. Paulo, jornal de maior circulação nacional nas últimas três décadas (cf. COM..., 2019). O corpus foi enumerado e organizado de um a cinco, apresentando o título e o lead de cada notícia (Quadro 1). 


\begin{tabular}{|c|c|c|}
\hline $\mathrm{N}^{\circ}$ & TÍTULO & $L E A D$ \\
\hline & $\begin{array}{l}\text { Ministério da Saúde irá ampliar para } 22,9 \text { milhões } \\
\text { total de testes para novo coronavírus }\end{array}$ & $\begin{array}{l}\text { Nova oferta deve abranger exames rápidos e } \\
\text { laboratoriais; pasta avalia ampliar testagem de casos } \\
\text { leves em cidades maiores }\end{array}$ \\
\hline & $\begin{array}{l}\text { Pandemia de coronavírus gera corrida global por } \\
\text { vacinas, medicamentos e diagnósticos }\end{array}$ & $\begin{array}{l}\text { Experimentos vão de novos usos para velhos } \\
\text { remédios a técnicas inovadoras de imunização }\end{array}$ \\
\hline & $\begin{array}{l}\text { Presidente da Palmares diz que isolamento é 'maior } \\
\text { imbecilidade da história' }\end{array}$ & $\begin{array}{l}\text { Medida decretada por governos de todo o Brasil é } \\
\text { considerada uma das mais eficazes na contenção do } \\
\text { coronavírus }\end{array}$ \\
\hline & $\begin{array}{l}\text { 'Não vai ser uma gripezinha que vai me derrubar', } \\
\text { diz Bolsonaro sobre coronavírus }\end{array}$ & $\begin{array}{l}\text { Presidente disse que só fará um novo exame para a } \\
\text { doença se for recomendado por seu médico }\end{array}$ \\
\hline & $\begin{array}{l}\text { Em pronunciamento, Bolsonaro critica fechamento } \\
\text { de escolas, ataca governadores e culpa mídia }\end{array}$ & $\begin{array}{l}\text { Fala do presidente foi acompanhada por panelaços } \\
\text { em cidades do país pelo oitavo dia seguido }\end{array}$ \\
\hline
\end{tabular}

\section{Quadro 1 - Títulos e leads de notícias sobre Covid-19}

Fonte: Corpus da pesquisa.

A constituição do corpus foi resultado da seleção de textos recentes, publicados entre 20 e 24 de março de 2020, que se demonstraram mais representativos para a elucidação de como o discurso jornalístico se utiliza da voz da ciência e da voz do idiota na composição dos enunciados sobre a pandemia de Covid-19 no Brasil (cf. CANCIAN; 2020; COLETTA, 2020; LOPES; 2020; PRESIDENTE..., 2020; URIBE; CHAIB; COLETTA, 2020). Segue nossa análise.

3 ANÁLISE DOS TÍTULOS E LEADS

Os enunciados em análise estão ligados às condições concretas do Brasil em tempos da pandemia de Covid-19, coronavírus. Muitas informações chegam diariamente ao nosso conhecimento, pelas redes sociais, por programas de televisão, telejornais e, em especial, por notícias que se multiplicam ao passo que surgem novidades sobre o tema. Em se tratando das notícias, a interação entre o jornalista e seus interlocutores é realizada, inicialmente, por meio da leitura dos títulos e dos leads que expressam um todo de sentido pretendido na informação veiculada nesse gênero do discurso. Além disso, já possibilita reações-resposta do interlocutor na adesão ou não a um determinado ponto de vista.

No gênero do discurso notícia, a composição do enunciado surge, muitas vezes, com o objetivo de popularizar o discurso científico e convencer a sociedade a cumprir as recomendações médicas para evitar o agravamento da pandemia e o colapso do sistema de saúde, sendo, uma dessas medidas, o isolamento social. Título, também conhecido como manchete, lead e corpo da notícia se integram em um texto de registro predominantemente formal, relativamente curto, informativo, descritivo ou narrativo sobre fatos reais (factual), atuais e cotidianos.

A análise revelou que, dos cinco títulos de notícias seguidos de seus respectivos leads, dois deles se bivocalizam com o discurso científico para informar sobre a pandemia com base em fatos e dados ( 1 e 2), enquanto três outros se bivocalizam com o discurso bolsonarista para trazer posicionamentos que negam a real problemática $(3,4$ e 5$)$.

Nos dois primeiros títulos e leads, é possível flagrar, em sua constituição, o que denominamos voz da ciência. São excertos típicos da bivocalidade assumida pelo 
discurso jornalístico com o discurso científico, trazendo marcas linguísticas próprias do campo de atividade da ciência, elementos que ajudam a constituir socialmente o próprio gênero notícia. A linguagem factual é uma dessas marcas, e a relação dialógica do título com o lead se estabelece de forma complementar, não polêmica.

O título Ministério da Saúde irá ampliar para 22,9 milhões total de testes para novo coronavírus (1) narra uma previsão de ação que acontecerá em momento posterior à notícia, atribuindo um tom de certeza pelo uso estilizado do tempo verbal futuro, indicando um certo protagonismo ao Ministério da Saúde no combate à pandemia de Covid-19 por meio da ampliação de testes que diagnosticam o vírus. O lead Nova oferta deve abranger exames rápidos e laboratoriais; pasta avalia ampliar testagem de casos leves em cidades maiores (1) reforça a ampliação da ação em tela, por meio da semântica dos verbos abranger e ampliar, além da inclusão de exames rápidos e laboratoriais, com especial atenção, ainda, para cidades maiores. No entanto, ao utilizar o verbo dever, como modalizador do discurso na expressão deve abranger, e o verbo avaliar, em avalia ampliar, o enunciador tinge o discurso jornalístico com o tom hipotético. Com isso, título e lead procuram provocar uma reação-reposta no interlocutor preocupado com a atual situação pandêmica de Covid-19 no Brasil: uma certa tranquilidade ao informar que o Ministério da Saúde está tomando medidas que favoreçam a ampliação do diagnóstico do coronavírus, por meio de testes, exames rápidos e laboratoriais, embora apreciadas pela não garantia de seus desdobramentos. O léxico selecionado caracteriza a voz da ciência, evidenciando as relações dialógicas entre o discurso jornalístico e o discurso científíco. Essas relações, portanto, delimitam o enunciado como uma resposta que supõe e confirma o conhecimento científico produzido anteriormente, atestando a gravidade do coronavírus, ao passo que busca tranquilizar seus interlocutores diante da assunção da pandemia.

O título Pandemia de coronavírus gera corrida global por vacinas, medicamentos e diagnósticos (2), por meio do léxico vacinas, medicamentos e diagnóstico, expressa o conhecimento produzido pela pesquisa experimental que busca dar um retorno à sociedade em relação ao combate à pandemia, dando expressividade à voz da ciência. $\mathrm{O}$ excerto corrida global dá o tom de urgência a essas medidas; se existe uma corrida global, é porque a infecção viral é grave e exige cuidados imediatos. Além disso, o termo global evidencia o caráter amplo dessa campanha, que extrapola os limites fronteiriços do que se compreende por nação, tornando-se uma agenda mundial. A voz da ciência se faz traduzida em uma língua sem fronteiras, sem nacionalidade, caracterizando a propriedade universal reivindicada pela ciência empírica. Já o lead Experimentos vão de novos usos para velhos remédios a técnicas inovadoras de imunização (2) maximiza o esforço dos cientistas em encontrar a solução para a pandemia de Covid-19, por meio da valoração positiva em relação ao agir científico. Essa valoração se dá pelo jogo de palavras novos usos/velhos remédios, bem como a adjetivação em técnicas inovadoras, que ao se bivocalizarem com o discurso científico, provocam a compreensão da evolução da pesquisa de natureza experimental, reverberando a voz da ciência como solução para o quadro pandêmico. A forma como o discurso jornalístico se bivocaliza com o discurso científico, criando o espaço para as relações dialógicas entre os enunciados, ajuda a construir o sentido produzido no discurso jornalístico sobre a pandemia no Brasil: uma 
situação que demanda inovação e comprometimento técnico por parte dos pesquisadores. Dessa forma, títulos e leads expressam um tom de cientificidade de modo a influenciar seu interlocutor, impessoalizando a palavra do outro, apoderando-se dos pontos de vista dos outros como se fosse seu, situação na qual "a voz penetrou neles, apoderou-se deles" (BAKHTIN, 1997, p. 350).

Os títulos 3, 4 e 5, por sua vez, repercutem o que denominamos voz do idiota, ponto de vista que é comprometido com a negação da atual situação de pandemia e, por conseguinte, da voz da ciência. O discurso citado do outro, a exemplo do discurso direto e indireto, marca, sintaticamente, a voz do idiota inserida no discurso jornalístico. A notícia que tem como propósito comunicativo a popularização da ciência mantém, com o discurso citado, uma relação de polêmica, reconstruindo, nos leads 3, 4 e 5, os pontos de vista sustentados pela voz do idiota.

O título Presidente da Palmares diz que isolamento é 'maior imbecilidade da história' (3) traz, por meio do discurso direto marcado por aspas simples, um ponto de vista que caracteriza o isolamento social como uma imbecilidade. A valoração negativa da medida de isolamento, marcada pelo termo imbecilidade, combate uma orientação de controle do quadro pandêmico no Brasil, já resultado da bivocalização entre os discursos jornalístico e científico, que trouxe uma voz da ciência difusa pelo horizonte semântico do léxico utilizado nos títulos e leads analisados anteriormente. Neste título de notícia, o discurso citado, portanto, expressa a voz do idiota, mobilizada pelo jornalista para marcar aquilo que nega o ponto de vista científico. O lead Medida decretada por governos de todo o Brasil é considerada uma das mais eficazes na contenção do coronavírus (3), por seu turno, apresenta a reação-resposta à voz do idiota. $\mathrm{O}$ enunciador salienta que a medida foi decretada por governadores de todo o Brasil para informar a amplitude do tema e construir, por meio da estruturação da voz passiva é considerada e da valoração produzida pelo adjetivo eficazes, uma verdade inquestionável de um sujeito omitido, produzindo um alguém diz, isto é, um status de verdade para o que é dito, que evidencia o propósito comunicativo desta notícia. As relações dialógicas de polêmica no título e no lead constroem o projeto de dizer da notícia e revelam o todo de sentido: refutar a voz do idiota, distanciando-se dela por meio do uso do discurso direto.

O título 'Não vai ser uma gripezinha que vai me derrubar', diz Bolsonaro sobre coronavírus (4) traz a voz do presidente do Brasil por meio do discurso direto marcado por aspas simples. Bolsonaro, investido do papel social de presidente do país, menospreza a real gravidade da pandemia no contexto nacional e internacional, utilizando-se do diminutivo em seu juízo de valor gripezinha. O uso do diminutivo nesta valoração põe em questão o conhecimento científico produzido sobre o tema, entrando em uma relação dialógica com a voz da ciência, já flagrada em títulos e leads anteriormente analisados (1 e 2); neste caso, menosprezando-a. No lead Presidente disse que só fará um novo exame para a doença se for recomendado por seu médico (4), o jornalista manipula a voz do presidente, por meio do discurso indireto, para reconstruir a valoração em torno da gravidade do que ele classificou de uma gripezinha, sugerindo que até mesmo quem nega a gravidade do coronavírus deve se submeter ao exame por recomendação médica. $\mathrm{O}$ discurso indireto, mesmo sugerindo essa polêmica velada com o título, ainda traz o eco da voz do idiota que constitui o título da notícia, pois a recomendação médica, em só fará 
um novo exame, é subordinada a uma oração condicional iniciada pela partícula se e particulariza essas recomendações em um único indivíduo, seu médico, como se essa autoridade específica pudesse ser maior do que orientações oriundas de conhecimento científico, atualizado independentemente de quem exerce a profissão da medicina. Título e lead, neste caso, apresentam relações dialógicas entre si constituídas pelo embate entre a voz do idiota contra a voz da ciência, de maneira muito velada, isto é, mesmo por meio do discurso citado, a notícia promove a relevância do conhecimento científico sobre a pandemia de Covid-19.

O título Bolsonaro critica fechamento de escolas, ataca governadores e culpa mídia (5), por último, apresenta outro exemplo do discurso citado do presidente do Brasil. A estratégia de inserção do discurso do presidente no título da notícia é iniciada pelo uso do verbo criticar, que recebe tom elocutório e o expande aos demais verbos, atacar e culpar, usados no presente do indicativo para expressar a fala do presidente. A semântica dos verbos selecionados pelo jornalista avalia a reação-resposta do presidente contra os enunciados constituídos pela voz da ciência, combatendo as orientações para o controle da pandemia a respeito do isolamento social que tem sido normatizado por demais agentes políticos do poder executivo e divulgado positivamente pela mídia. O sentido produzido pelo discurso citado e pelos tons apreciativos dos recursos linguísticos dão acabamento ao projeto de dizer do jornalista, construindo um dizer sobre o dito, no qual a fala do presidente já é avaliada pela voz do jornalista: ouvem-se as duas vozes. Coloca-se a voz do presidente como ponto de vista que nega a materialidade histórica e constrói uma guerra imaginária, em que o inimigo a ser combatido é representado pela tríade ação de controle, governadores e mídia. O discurso jornalístico se utiliza da voz do outro que menospreza os enunciados que orientam para a preservação da vida em escala mundial. Isso corrobora o pensamento bakhtiniano de que o discurso, de fato, se utiliza de muitas estratégias para se bivocalizar, sendo uma delas o revestimento dessas vozes de nossas próprias intenções (BAKHTIN 2018). Dessa forma, ele constrói, nos pontos em que se tocam dialogicamente os enunciados, a expressão concreto-semântica da voz do idiota.

O lead Fala do presidente foi acompanhada por panelaços em cidades do país pelo oitavo dia seguido (5) tanto constitui uma reação-resposta ao próprio discurso citado do presidente, como demonstra que seu pronunciamento gerou uma atitude responsiva ativa na população. O texto polemiza abertamente com o ponto de vista anticientificista materializado na voz do idiota, relatando que panelaços responderam, em forma de protesto, ao enunciado primeiro. Vale salientar que o panelaço é uma forma de protesto conhecida pelos brasileiros da classe média, que se utiliza desse recurso na tentativa de destituição de agentes de seus cargos políticos, ou seja, a atitude responsiva ativa bater de panelas reivindica o impedimento do mandato presidencial de forma sistemática e contínua, pois se manifesta pelo oitavo dia seguido. O discurso jornalístico, ao trazer o panelaço como contraponto ao discurso presidencial, produz o efeito de sentido de que a população está insatisfeita com posturas de quem ignora o bem-estar social e não se preocupa com a vida dos cidadãos brasileiros. O barulho provocado pelo panelaço sufoca enunciados imbuídos pela voz do idiota que nega as orientações dos órgãos oficiais de saúde. Ao fazê-lo, o panelaço dá o tom da melodia polifônica aos gritos de "Fora Bolsonaro!" que ecoam pelas cidades do país em tempos da pandemia de Covid-19 e que apontam para o caráter inacabado do enunciado, no qual a última palavra nunca é dita. 
Dada a análise, os resultados apontam que a voz da ciência é expressa por meio da mobilização de léxico de natureza específica da esfera da comunicação científica, enquanto a voz do idiota é revelada por meio do discurso citado que menospreza as orientações para o combate da pandemia, despreza seus efeitos e cria uma guerra imaginária em que a mídia é seu principal inimigo. A voz da ciência é a expressão do ponto de vista científico, quando bivocalizado no discurso jornalístico, atestando para a gravidade da pandemia. A voz do idiota é a expressão do ponto de vista bolsonarista, quando bivocalizado no discurso jornalístico, menosprezando e negando a voz da ciência. Assim, o discurso jornalístico constrói-se como palco da disputa na produção de sentido atribuído ao objeto de discurso Covid-19, escolhendo, previamente, o seu lado no embate. As relações dialógicas entre as vozes sociais no discurso jornalístico pressupõem o propósito comunicativo do gênero notícia por meio da função de seus títulos e leads no contexto em tela, qual seja, negar a voz do idiota ao bivocalizar-se difusamente com a voz da ciência. Em outros termos, "O sentido se distribui entre as diversas vozes" (BAKHTIN, 1997, p. 317).

Em síntese, a análise das relações dialógicas evidenciou que o discurso jornalístico, ao se bivocalizar com o discurso científico, expressa a voz da ciência de maneira difusa; cria uma arena de disputa entre a voz da ciência e a voz do idiota, trazendo valorações anticientificistas ao se bivocalizar com o discurso bolsonarista; desacredita a voz do idiota, distanciando-se dela por meio do discurso citado, produzindo os sentidos sobre a Covid-19.

\section{CONSIDERAÇÕES FINAIS}

Neste artigo, observamos como o discurso jornalístico se utilizou da voz da ciência, que se ampara no conhecimento científico, e da voz do idiota, que combate a voz da ciência, para compor os enunciados sobre a pandemia Covid-19 no Brasil. Para tanto, foi necessário percorrermos um caminho teórico-metodológico capaz de sustentar, por via da Análise Dialógica do Discurso (ADD), as premissas que consideram o enunciado concreto como unidade de análise, composto por diversos pontos de vista sobre o mundo que, quando enunciado, tinge as palavras da língua de muitas intenções.

O gênero do discurso notícia, como já assinalou Bakhtin (2015), é potencial de transmissão, ponderação, recordação, discussão das palavras/opiniões alheias. Com isso, a publicação de uma notícia, além de responder a enunciados anteriores sobre um dado tema, é forjada na cadeia dialógica, antecipando uma resposta futura, cunhando, no horizonte social, opiniões, atitudes e valores, transformando o discurso jornalístico em palco para a disputa de diferentes pontos de vista, conforme flagrado por meio da análise das relações dialógicas das vozes sociais nos títulos e leads desta investigação.

Quando a pandemia de Covid-19 no Brasil foi tematizada nas notícias extraídas da página do jornal Folha de S. Paulo, percebemos que dois pontos de vista opostos se consolidavam na materialidade discursiva e na luta pela consciência dos sujeitos da interação verbal: a voz da ciência e a voz do idiota. A voz da ciência foi de tal forma bivocalizada com o discurso jornalístico, em uma pretensa unificação, que a recuperação dos pontos de vista da esfera científica só foi possível de maneira difusa, pelos elementos linguístico-discursivos que caracterizam a linguagem de um grupo, de uma profissão, via utilização de jargões e léxico próprios daquela esfera. 
Por outro lado, quando repercute a voz do idiota, o discurso jornalístico utilizou as formas marcadas do discurso do outro, pessoalizando o discurso citado. Dessa forma, títulos e leads se distanciam das opiniões que contrapunham o ponto de vista científico. A utilização dos variados recursos linguístico-discursivos utilizados para construir o projeto de dizer do discurso jornalístico reafirma que a língua é ideologicamente preenchida, uma opinião concreta sobre o mundo, uma realidade viva e social que se renova em cada novo enunciado, único e irrepetível, mas aberto para novas modalidades de compreensão a partir do horizonte social do outro.

A análise realizada neste artigo, inserida nos princípios da Análise Dialógica do Discurso, pressupôs que "A visão do mundo, a tendência, o ponto de vista, a opinião têm sempre sua expressão verbal. É isso que constitui o discurso do outro (de uma forma pessoal ou impessoal), e esse discurso não pode deixar de repercutir no enunciado." (BAKHTIN, 1997, p. 321). Dessa forma, reafirmamos que as relações dialógicas nas notícias do site do jornal Folha de S. Paulo constroem um todo de sentido que revela seu posicionamento axiológico: negar a $\mathrm{voz}$ do idiota recorrendo à voz derivada do contexto científico, demonstrando que, antes de mais nada, a palavra é portadora de valoração social.

\section{REFERÊNCIAS}

ACOSTA PEREIRA, R; BRAIT, B. Revisitando o estudo/estatuto dialógico da palavra. Linguagem em (Dis)curso, Tubarão, v. 1, n. 1, p. 125-142, jan./abr. 2020.

AHMED, Q. A.; MEMISH, Z. A. The cancellation of mass gatherings (MGs)? Decision making in the time of COVID-19. Travel Medicine and Infectious Disease, [s.1.], p.1-4, mar. 2020.

ALBARELLO, P. S.; PINHEIRO, N. F. Polifonia como estratégia no processo de recontextualização da ciência no gênero reportagem televisiva. Domínios de Lingu@gem, [S.L.], v. 11, n. 4, p. 1344, out./dez. 2017.

BAKHTIN, M. M. (VOLOCHÍNOV). Marxismo e Filosofia da Linguagem. 12. ed. Tradução de Michel Lahud e Yara Frateschi Vieira. São Paulo: HUCITEC, 2006.

BAKHTIN, M. M. Estética da criação verbal. Tradução do francês por Maria Ermantina Galvão G. Pereira. Revisão da tradução Marina Appenzeller. 2. ed. São Paulo: Martins Fontes, 1997.

BAKHTIN, M. M. Problemas da poética de Dostoiévsky. Tradução de Paulo Bezerra. 5. ed. Rio de Janeiro: Forense Universitária, 2018.

BAKHTIN. M. M. Teoria do romance I: A estilística. Tradução de Paulo Bezerra. São Paulo: 34, 2015.

BENITES, S. A. L.; SILVA, D. R. O dialogismo no gênero discursivo notícia. Acta Scientiarum.

Language and Culture, Maringá, v. 37, n. 4, p. 347-357, Oct.-Dec. 2015.

BRAIT, B. Análise e Teoria do discurso. In: BRAIT, B. (Org.). Bakhtin: outros conceitos-chave. 2. ed. 2. reimpr. São Paulo: Contexto, 2016.

COMASSETTO, L. R. As razões do título e do lead: uma abordagem cognitiva da estrutura da notícia. 2001. 99f. Dissertação (Mestrado em Lingüística) - Programa de Pós-graduação em Letras/Linguística, Universidade Federal de Santa Catarina, 2001.

DARDE, V. W. S. As vozes da AIDS na imprensa: um estudo das fontes de informação dos jornais Folha de S. Paulo e O Globo. 2006. 186f. Dissertação (Mestrado em Comunicação e Informação) - Programa de Pós-Graduação em Comunicação e Informação, Universidade Federal do Rio Grande do Sul, 2006.

DELEUZE, G. O abecedário de Gilles Deleuze. Entrevista. Realizado por Pierre-André Boutang. França: Éditions Montparnasse, 1989.

LIMA, Samuel de Carvalho; BASTOS, Rafael Lira Gomes. A produção de sentido no discurso jornalístico sobre a pandemia de Covid-19 no Brasil. Linguagem em (Dis)curso - LemD, Tubarão, SC, v. 21, n. 2, p. 253-265, maio/ago. 2021. 
GONÇALVES, J. B. C.; AMARAL, M. R. S. Análise dialógica do discurso orientada para o texto: o dialogismo interno e a bivocalidade no poema Ela e Você, de Arnaldo Antunes. Letras em Revista, [S.1.], v. 8 , n. $01,2017$.

LONGHI, R.; FERREIRA, L. T. Dialogismo: as vozes em notícias de um estupro coletivo. Entrepalavras, Fortaleza, v. 8, n. 2, p.80-99, maio/ago. 2018.

LOPES, R. J. Pandemia de coronavírus gera corrida global por vacinas, medicamentos e diagnósticos. $O$ Estado de S. Paulo, [S. l.], p. 1, 24 mar. 2020.

OLIVEIRA, M. B. Um olhar bakhtiniano sobre a pesquisa nos estudos do discurso. Filologia e Linguística Portuguesa, [s.1.], v. 14, n. 2, p. 265-284, 2012.

PAIVA, F. J. O.; BATISTA JÚNIOR, J. R. L. O discurso bolsonarista em metáforas multimodais sobre a flexibilização da posse de armas: uma análise dialético-relacional no gênero charge. Revista Letras Raras, v. 8, n. 2, p. 58-79, 2019.

SHEREEN, M. A.; KHAN, S.; KAZMI, A.; BASHIR, N.; SIDDIQUE, R. COVID-19 infection: origin, transmission, and characteristics of human coronaviruses. Journal of Advanced Research, [s.1.], p.1-26, mar. 2020.

SIPRIANO, B. F. GONÇALVES, J. B. C. O conceito de vozes sociais na teoria bakhtiniana. Revista Diálogos, Cuiabá, v. 5, n. 1, p. 60-80, 2017.

SOBRAL, A; GIACOMELLI, K. Observações didáticas sobre a análise dialógica do discurso ADD. Domínios de Lingu@gem, Uberlândia, v. 10, n. 3, p.1076-1094, jul./set. 2016.

SOBRAL, A.; GIACOMELLI, K. Das significações na língua ao sentido na linguagem: parâmetros para uma análise dialógica. Linguagem em (dis)curso, Tubarão, v. 18, n. 2, p.307-322, maio-ago. 2018.

TINTINO FILHO, D. Cartografias do desejo em asfalto selvagem - engraçadinha, seus amores e seus pecados: humor, erotismo e o pornógrafo no romance rodrigueano. 2013. 123f. Dissertação (Mestrado em Linguística Aplicada; Literatura Comparada) - Programa de Pós-Graduação em Estudos da Linguagem, Centro de Ciências Humanas, Universidade Federal do Rio Grande do Norte, 2013.

\section{DADOS DE CORPUS}

CANCIAN, N. Ministério da Saúde ampliará para 22,9 milhões total de testes para novo coronavírus. $O$ Estado de S. Paulo, [S. l.], p. 1, 24 mar. 2020.

COLETTA, R. D. Em pronunciamento, Bolsonaro critica fechamento de escolas, ataca governadores e culpa mídia. O Estado de S. Paulo, [S. l.], p. 1, 24 mar. 2020.

COM crescimento digital, Folha lidera circulação total entre jornais brasileiros. Folha de S. Paulo, São Paulo, p. 1, 21 abr. 2019.

LOPES, R. J. Pandemia de coronavírus gera corrida global por vacinas, medicamentos e diagnósticos. $O$ Estado de S. Paulo, [S. l.], p. 1, 24 mar. 2020.

PRESIDENTE da Palmares diz que isolamento é 'maior imbecilidade da história'. O Estado de S. Paulo, [S. l.], p. 1, 24 mar. 2020.

URIBE, G.; CHAIB, J.; COLETTA, R. D. ‘Não vai ser uma gripezinha que vai me derrubar', diz Bolsonaro sobre coronavírus. O Estado de S. Paulo, [S. l.], p. 1, 26 mar. 2020.

\section{AGRADECIMENTOS}

Agradecemos aos pareceristas da revista Linguagem em (Dis)curso pelas contribuições e revisões no texto original. $\mathrm{O}$ trabalho voluntário desses profissionais contribuiu de forma decisiva para a qualidade final deste manuscrito.

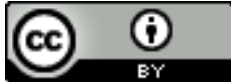

Este texto está licenciado com uma Licença Creative Commons Atribuição 4.0 Internacional.

LIMA, Samuel de Carvalho; BASTOS, Rafael Lira Gomes. A produção de sentido no discurso jornalístico sobre a pandemia de Covid-19 no Brasil. Linguagem em (Dis)curso - LemD, Tubarão, SC, v. 21, n. 2, p. 253-265, maio/ago. 2021. 